ESCRITAS Vol. 11 n. 2 (2018) ISSN 2238-7188 p.177-192

\title{
TRAJETÓRIA DAS FREIRAS ENFERMEIRAS NA SANTA CASA DE MISERICÓRDIA DE CACHOEIRO DE ITAPEMIRIM (1929-1950)
}

\author{
TRAJECTORY OF NURSES NURSES IN THE HOLY HOUSE OF \\ MISERICÓRDIA DE CACHOEIRO DE ITAPEMIRIM (1929-1950
}

Luciene Carla Corrêa Francelino ${ }^{1}$

\section{RESUMO:}

A pesquisa tem como objeto de análise a atuação das religiosas da congregação de Jesus na Santíssima Eucaristia, no interior da Santa Casa de Misericórdia de Cachoeiro de Itapemirim - município localizado no sul do estado do Espírito Santo - entre os anos de 1929 a 1950 . A escolha do período deve-se ao momento em que as freiras passam a administrar vários setores da instituição, à exemplo: centro cirúrgico, maternidade, lavanderia e rouparia. Embora não possuíssem conhecimentos técnicos sobre enfermagem, atuavam como tais, no cotidiano do nosocômio. A data que finaliza a pesquisa é referente ao momento em que as religiosas deixam de administrar o hospital. Pretendemos problematizar os conceitos de vocação religiosa no âmbito da congregação, enfatizando os diversos fatores que influenciaram a escolha pela vida eclesiástica. Outrossim, destacaremos a institucionalização da enfermagem no Brasil na década de 1930 e a repercussão desta no cotidiano das irmãs que atuavam na Santa Casa.

PALAVRAS-CHAVE: Freiras; Vocação; Profissão; Enfermagem; Santa Casa.

\begin{abstract}
:
The research has as its object the analysis of the performance of the religious of the congregation of Jesus in the Holy Eucharist, in the interior of the Holy House of Mercy of Cachoeiro de Itapemirim, a municipality located in the south of the state of Espirito Santo, between 1929 and 1950. choice of the period is due to the moment in which the nuns start to administer several sectors of the institution, for example: surgical center, maternity, laundry and linen cloth. Although they did not have technical knowledge about nursing, they acted as such in the daily life of the hospital. The date of completion of the survey refers to the time when the religious leave the hospital. We intend to problematize the concepts of religious vocation within the congregation, emphasizing the various factors that influenced the choice for ecclesiastical life. Also, we will highlight the institutionalization of nursing in Brazil in the 1930s and the repercussion of this in the daily life of the sisters who worked in the Santa Casa.
\end{abstract}

KEYWORDS: Nuns; Vocation; Profession; Nursing; Holy House.

\footnotetext{
${ }^{1}$ Universidade Federal do Espírito Santo - lucienecarla20@hotmail.com
} 


\section{INTRODUÇÃO}

A história do cristianismo foi marcada, desde o início por mulheres que dedicaram suas vidas a servir a Deus, vivendo em constante oração e praticando a caridade através do auxílio ao próximo. De acordo com Algranti (1993) no período em que Roma se estabeleceu como "Grande Império", muitas mulheres, denominadas virgens consagradas, passaram a viver isoladas em casas ou comunidades, onde recebiam orientação religiosa de outra mulher mais velha e experiente. Muitas delas não eram necessariamente virgens, mas viúvas que faziam opção pela vida contemplativa, renunciando a uma segunda núpcias. A partir do século V, surgiram as primeiras ordens monásticas de mulheres. Santo Agostinho ${ }^{2}$ (354-430) conferiu a estas ordens, regras religiosas semelhantes à dos homens. No século seguinte, o bispo Cesário de Arles $^{3}$ escreveu a primeira "Regra" essencialmente para monjas do convento feminino de sua vila. O documento continha 43 capítulos, nos quais determinava as qualidades essenciais às abadessas, baseadas em vida comunitária, com destaque para a reclusão.

A primeira lei com caráter universal para a clausura ${ }^{4}$ foi a Constituição Peticulosa de 1298, instituída pelo papa Bonifácio VIII $^{5}$, que proibia determinantemente a saída das

\footnotetext{
${ }^{2}$ Agostinho de Hipona foi um dos mais influentes filósofos dos primórdios do cristianismo. Nasceu em 354, em Tago, na África romana. Aos 17 anos mudou-se para Cartago onde estudou e ministrou aulas de retórica e, em 386 converteu-se ao cristianismo. Dois anos depois sua mãe faleceu, em seguida teve que lidar com a morte do filho Adeodato, fruto de um relacionamento de 13 anos com uma concubina. Entristecido, vendeu os bens da família e doou aos pobres, manteve apenas uma casa na qual transformou em mosteiro para si e seus amigos. No ano de 341 foi ordenado sacerdote, tornando-se um pregador muito influente, autor de mais de 300 famosos sermões. No ano 395 tornou-se bispo de Hipona, nessa época empreendeu grandes esforços para converter o povo da região. Apesar de ter deixado o mosteiro continuou levando vida modesta na residência episcopal, para seus antigos companheiros deixou uma Regra de vida conhecida como Regra de Santo Agostinho, na qual continha os princípios da vida monástica, por isso é considerado por muitos como o padroeiro do clero regular. Foi um profícuo autor com uma lista de mais de 100 títulos diferentes, dos quais constam obras contra heresias, textos sobre doutrina cristã, comentários de textos bíblicos, sermões, entre outros. Para saber mais sobre o tema ver Brown (2005).

${ }^{3}$ Filho de burgúndios, Cesário nasceu em 470, em Chalon-sur-Saonê, no período em que os reis germânicos regiam a Borgonha. Ingressou na vida religiosa desde a adolescência, formando-se monge pelo mosteiro de Lérins, desde então passou a estudar as escrituras com a finalidade de melhorar a organização da vida cristã. Foi consagrado bispo em 502, com aproximadamente 32 anos de idade. Esforçou-se para induzir os leigos a participarem do ofício sagrado e orientava os fiéis a lerem constantemente a Bíblia. Em 512 fundou o mosteiro de São João de Arles, onde sua irmã era abadessa, dois anos mais tarde tornou-se vigário da Sé apostólica para Gália e Espanha. A partir de então convocou e presidiu vários concílios, nos quais muitas de suas ideias foram adotadas. Para Saber mais sobre o assunto ver Bardy (1947).

${ }^{4}$ A clausura é composta por um conjunto de leis que restringem ou limitam a entrada e permanência de estranhos no espaço onde vivem religiosos ou religiosas de determinada Ordem religiosa, bem como a saída destes para além desse espaço de reclusão. O principal objetivo do recolhimento dessas pessoas era a castidade e a
} 
religiosas dos conventos, salvo em casos de doença contagiosa que pudesse colocar em risco toda a comunidade. No século XVI, o papa Pio $\mathrm{V}^{6}$ determinou que a saída da reclusão só poderia acontecer em casos de incêndio, lepra - ou outra doença contagiosa -, ruína do edifício que abrigasse tais mulheres ou em ameaça iminente de guerra, mas em todas as situações era necessário pedir autorização por escrito à respectiva autoridade eclesiástica responsável. Destarte, no século XVII, a vida religiosa monástica tinha como princípio basilar a clausura (FERNANDES, 1992).

O trabalho junto aos doentes foi uma das práticas caritativas que ao longo dos séculos aliou-se à história da enfermagem. Diversas ordens religiosas foram criadas para prestar assistência aos desvalidos, esses ideais de amor ao próximo, marcaram o desenvolvimento da enfermagem, estabelecendo um modelo comportamental para o cuidado com os enfermos (DONAHUE, 1993).

A Companhia das Irmãs de Caridade foi fundada em 1633 na França, pelo padre Vicente de Paulo e pela religiosa Luísa de Marillac. O momento em que essa ordem foi criada coincide com o período em que a miséria e as doenças causadas por longos anos de guerras estavam arruinando o país. A irmandade tinha o compromisso de alimentar os pobres, realizar trabalhos de assistência espiritual nos lares e cuidar dos doentes nos hospitais, além de reorganizar tais espaços, implementando princípios higiênicos através da individualização dos leitos. De acordo com (Castro, 1936) a Companhia das Irmãs de Caridade foi fundada para que houvessem mulheres que servissem apenas aos necessitados, por tempo integral, sem outras ocupações relacionadas à vida pessoal, como casamento e família. O treinamento dessas jovens devia ser de poucas palavras, havendo momentos destinados para o exercício da catequese e cuidados domésticos. Os comandos eram dados através de olhares, gestos ou

manutenção de uma vida em constante comunhão com Deus através da oração e do distanciamento das tentações mundanas.

${ }^{5}$ Nasceu Benedetto Gaetani no ano 1234, em Anagni, à $50 \mathrm{~km}$ de Roma. Era filho mais novo de uma família de nobres de Lombardia, que anos anteriores havia gerado um papa, Gelásio II. Era versado em teologia, direito romano e direito eclesiástico. Tornou-se sacerdote em 1260 e quatro anos mais tarde passou a integrar a cúria romana, acumulando vários cargos ao longo dos anos até tornar-se cardeal, servindo de legado papal em várias negociações diplomáticas. Foi eleito papa em 1294 após a abdicação de Celestino V. Para maiores esclarecimentos ver Wollpert (1998).

${ }^{6}$ Seu nome de batismo era Antonio Ghislieri, nasceu em 1504, no ducado de Milão, na Itália. Aos 14 anos de idade ingressou na Ordem dos Pregadores de Voghera. Em 1528 foi ordenado presbítero em Gênova e enviado para Pavia onde escreveu 30 teses em defesa da cátedra de Pedro e contra o que considerava ser as heresias de seu tempo. Era considerado um enérgico instrutor doutrinário, por isso, tornou-se inquisidor em Como. Nos anos seguintes, foi empossado comissário da Santa Sé e bispo. Após a morte de Pio IV, foi eleito papa em 1556, conhecido por aplicar de forma enérgica as decisões do Concílio de Trento, reestabelecendo entre os religiosos os princípios morais essências à vida eclesiástica, entre eles a ascese, ou seja, o autocontrole do corporal e espiritual. Combateu com veemência a Reforma Protestante. Para mais informações sobre Pio V ver Frattini (2009). 
palmas, evocando a moral e a obediência. O ensino da enfermagem era ministrado pela Superiora às demais Irmãs, através de cartas explicativas ou por meio da prática cotidiana. Não havia ainda um manual escrito ou organização técnica, mas a implementação das ações relacionadas ao cuidado com os enfermos se aproximava do que viria futuramente a ser as "técnicas de enfermagem".

Florence Nightingale é considerada fundadora da Enfermagem moderna, nasceu em 12 de maio de 1820 em Florença, numa família abastada. Estudou diversos idiomas, além de religião, filosofia e matemática, era extremamente religiosa e desde muito cedo apresentava o desejo de ajudar aos pobres e necessitados. Participou como voluntária na Guerra da Crimeia em 1854, quando juntamente com 38 mulheres (irmãs católicas e anglicanas) organizou um hospital com 4.000 mil soldados internos, conseguindo baixar a mortalidade que era de $40 \%$ para $2 \%$. Recebeu um prêmio do governo inglês em virtude desse trabalho e fundou a primeira escola de Enfermagem no Hospital St. Thomas em Londres no ano de 1860. Conheceu o trabalho realizado pelas Irmãs de Caridade de São Vicente de Paulo em Paris, no Hôtel-dieu, acompanhando de perto o trabalho administrativo e assistencial que estas realizavam, tendo acesso às regras que norteavam o trabalho das religiosas, o modo como cuidavam dos doentes, aprofundando seus estudos através de anotações, gráficos e listas das atividades desenvolvidas. Em outro momento, retornou ao hospital, permanecendo ali por um mês, vestindo o hábito das Irmãs, para sentir o carisma - chamado vocacional para a lida com os necessitados - o convívio com as religiosas no interior do hospital, certamente influenciou a maneira como Nightingale estruturou o seu modelo de Enfermagem (PADILHA; MANCIA, 2005).

No Brasil a vinda das Irmãs de São Vicente de Paula data de 1849, quando o bispo da cidade mineira de Mariana, pediu ao Superior Geral da Companhia, que enviasse algumas religiosas para atuarem como enfermeiras junto aos escravos e demais doentes da região. No dia 3 de abril de 1849 chegava à região 12 irmãs de caridade, que logo se dedicaram a visitar os necessitados e cuidar dos doentes do hospital Nossa Senhora das Vitórias. Essas freiras fundaram a primeira casa das Filhas de Caridade no Brasil, denominada Casa da Providência, neste local de residência, as religiosas fabricavam produtos de limpeza, como: sabonetes, sabão líquido e brilhantina, sendo a venda destes produtos destinadas para as obras sociais que mantinham, como escolas e orfanatos (LAGE, 2010).

Na década de 1850 durante as epidemias de cólera e febre amarela, o imperador D. 
Pedro II solicitou a vinda de Irmãs Vicentinas para atuarem na Santa Casa do Rio de Janeiro. Estas chegaram no país em 1852 e assumiram os serviços de enfermagem, administrativo e religioso da Santa Casa. Bezerra (2002) assevera que através da Irmãs de Caridade a Igreja teve o reconhecimento de sua hegemonia no controle dos espaços hospitalares, além de implementar um modelo de enfermagem alicerçado nos princípios católicos. Nos anos seguintes, freiras passaram a atuar na administração das Santas Casas em várias partes do Brasil.

De acordo com Langlois (1984), foi a Revolução Francesa, em fins do século XVIII, que ocasionou a modificação do modelo de reclusão das religiosas que pertenciam a determinadas ordens. Isto porque a Revolução provocou a destruição de conventos, abadias e mosteiros, fazendo com que algumas congregações procurassem adaptar-se à nova realidade $\mathrm{e}$ necessidades da sociedade, cuidando de presos, órfãos e doentes. Após esse período de adversidade, as congregações femininas francesas passaram por um processo de expansão e muitas delas se instalaram em territórios além da França. O sucesso para a expansão das congregações se dava pela capacidade de adaptação desse modo de vida religioso aos lugares de instalação e a eficiência das freiras em dar respostas às necessidades das sociedades. Outrossim, havia a orientação para que executassem trabalhos de interesse social $^{7}$ e não apenas ofícios religiosos. Contudo, em fins do século XIX, as leis francesas de laicização ${ }^{8}$ acabaram inviabilizando a atuação de religiosos em espaços públicos, principalmente em colégios, então, a solução para inúmeras corporações foi migrar para outros locais. Rejeitados em seu país de origem, muitas dessas congregações foram acolhidas na América Latina, especialmente no Brasil. ${ }^{9}$

As Irmãs da ordem de São Vicente de Paulo realizavam várias atividades nos lugares onde se instalavam, em geral eram trabalhos relacionados ao cuidado de doentes e órfãos. No entanto, acompanhando o movimento de expansão da educação no decorrer do século XIX, passaram a se dedicar, também, à escolarização de meninas. Os ideais de caridade das Vicentinas serviram de modelo para a criação de novas congregações de vida ativa' a exemplo

\footnotetext{
${ }^{7} \mathrm{Se}$, por um lado, a Igreja ansiava por uma comunidade com Regra de vida, o Estado esperava que a mesma possuísse funções sociais junto à população, ou seja, o poder público necessitava do trabalho das irmãs de caridade e dos religiosos, principalmente em escolas e hospitais. Para saber mais ver Bittencourt (2004) e Langlois (1984).

${ }^{8}$ Nesse período, toda a Europa passava por um processo de laicização e expansão do pensamento liberal, em especial a Itália e a França.

9 Segundo Leonardi (2011), entre os anos de 1849 a 1912 mais de cinquenta congregações aportaram no Brasil, com o intuito de atuar nas áreas de educação e saúde.
} 
da congregação das Irmãs de Jesus na Santíssima Eucaristia, fundada por madre Gertrudes de São José, em 1927, no município de Cachoeiro de Itapemirim.

\section{A CONGREGAÇÃO DAS IRMÃS DE JESUS NA SANTÍSSIMA EUCARISTIA}

A congregação das Irmãs de Jesus na Santíssima Eucaristia foi fundada por madre Gertrudes de São José ${ }^{10}$ dia 10 de outubro de 1927 e recebeu, inicialmente, a denominação de Congregação das Irmãs de Cristo Rei. A irmandade era uma comunidade de vida ativa composta por mulheres vocacionadas que passam a ocupar importantes postos na sociedade cachoeirense, seja através do Colégio ou da atuação na Santa Casa do município.

A vocação religiosa geralmente é percebida como um chamamento divino, algo que estaria fora do alcance das análises históricas e sociológicas por se tratar de um fenômeno metafísico, no entanto, se o ser humano é sobretudo um ser histórico, podemos constatar que suas escolhas, visão de mundo e crenças estão impregnadas de resíduos culturais do meio social em que está inserido, portanto, passíveis de análise.

Seidl (2012) reflete acerca da atuação religiosa afirmando que há resistências em analisar a vocação eclesiástica como escolha profissional. Segundo o autor, o exercício religioso é encarado como missão em vez de carreira ou profissão. Para reforçar tal entendimento existe a recusa da esfera econômica do lucro, ou de um rendimento individual. ${ }^{11}$

\footnotetext{
${ }^{10}$ Nasceu na vila de Casacce, na cidade italiana de Chiuro, no dia 07 de agosto de 1876 . Seu nome de batismo, Martina Toloni. Filha de um alfaiate e de uma costureira, perdeu a mãe quando tinha apenas cinco anos de idade. Foi educada por freiras no orfanato Casa Della Providenza, onde recebeu o primeiro contato com a religiosidade. Tornou-se noviça em 1900 e após algumas experiências em congregações religiosas italianas, embarcou para o Brasil em 1904, para atuar junto aos necessitados. Trabalhou em hospitais e orfanatos no estado de São Paulo. Em 1911, ingressou na congregação de São José de Chambèry em Itu e passou a adotar o nome religioso de Gertrudes de São José. Peregrinou por diversas casas da congregação até ser acolhida pela irmandade Servas de Maria, no Rio de Janeiro. Em 1927 chegou ao sul do estado do Espírito Santo com a finalidade de recolher donativos para cobrir os custos de uma reforma feita em um colégio da irmandade Servas de Maria. Durante sua trajetória religiosa em vários momentos demonstrou o interesse de fundar a sua própria congregação. No município de Cachoeiro de Itapemirim, algumas senhoras de famílias abastadas confidenciaram a Gertrudes o interesse do estabelecimento de um colégio religioso para que suas filhas estudassem. Motivada pelo interesse de fundar uma congregação e um colégio, Gertrudes procura o bispo da arquidiocese do Espírito Santo e recebe do mesmo autorização para empreender os seus projetos na cidade de Cachoeiro de Itapemirim. A freira alugou uma casa para ser a sede da irmandade e do colégio. A congregação foi fundada em outubro de 1927 e o colégio iniciou suas atividades em fevereiro do ano seguinte (SÃO JOSÉ et al., 1990, p. 55-56).

${ }^{11}$ Membros das esferas eclesiásticas da Igreja Católica não recebem um salário individual para exercer o cargo ou funções pertinentes a vida religiosa. As Ordens que prestam serviços em hospitais ou escolas recebem um salário coletivo utilizado para investir na expansão e manutenção da irmandade e para suprir as necessidades de seus integrantes.
} 
Analisando os fatores que influenciam a escolha pela vida monástica, Suaud (1978) assevera que a aptidão, ou chamado religioso, passa, em primeira instância, pela esfera analítica, para, em seguida, tornar-se um anseio do indivíduo, isso porque o interesse individual está sujeito a outros interesses coletivos. $\mathrm{O}$ autor percebeu que, no primeiro quartel do século XX, era grande o contingente de vocações nas famílias camponesas de prole numerosa. Isso se dava, entre outros fatores, pela possibilidade de acesso à escolarização quando o filho ingressava em alguma Ordem religiosa, além do capital cultural que a família adquiria por ter um de seus membros nos quadros da Igreja. ${ }^{12}$

Ao examinarmos a vocação religiosa feminina no Brasil no início do século XX, não encontramos disparidades em relação aos incentivos externos ou às influências socioculturais no chamado eclesiástico das moças, sobretudo da zona rural. Nesse aspecto, o ingresso de uma filha de família camponesa em um convento estava muitas vezes relacionado ao desejo de desvencilhar-se de um casamento arranjado ou de questões de herança na partilha da propriedade entre uma prole numerosa. Sobre esse assunto, Moura (1978) destaca que se uma família numerosa pode representar garantia de mão-de-obra para o trabalho na propriedade, por outro lado, poderia acarretar a dilapidação do patrimônio em virtude da divisão de herança.

O ensaio de Miriam Pillar Grossi, intitulado Jeito de freira: estudo antropológico sobre a vocação religiosa feminina (1990), destaca que a opção pela vida consagrada pode ser analisada sob três aspectos: plano coletivo, que envolve anseios familiares; projetos individuais e proposta eclesiástica. Partindo da primeira perspectiva, a ida de uma filha para o convento muitas vezes acarreta conflitos no âmbito familiar, pois, mesmo que servindo para resolver questões de herança, esbarra em outros temas significativos para a família, na medida em que não ocorriam novos "acordos", como geralmente surgem na união matrimonial, que acabam envolvendo toda ou várias famílias, seja através do aumento patrimonial, transações comerciais ou instituição de sociedade. Outro fator relevante é a falta que uma filha poderia representar na provisão e cuidado dos pais na velhice. Aliado a estes fatores estava o ônus financeiro com o dote que a aspirante à vida religiosa precisa levar para o convento, além do

\footnotetext{
${ }^{12}$ O estudo de Suaud (1978) aborda as vocações sacerdotais em Vendeia, região localizada no sul do vale de Loire, à oeste da França. O local forneceu um grande número de sacerdotes à Igreja até os anos 1960, quando ocorreu um período de declínio das vocações religiosas.
} 
enxoval. ${ }^{13}$ Os contratempos e conflitos provocados em virtude da opção pela vida eclesiástica se diluíam quando a filha tornava-se finalmente freira. Tais questões cediam espaço para o prestígio familiar e na aquisição de capital simbólico na comunidade, principalmente entre as famílias da zona rural.

Analisando a vocação como um projeto individual, Grossi afirma que é inegável que muitas jovens percebiam o ingresso em um convento ou congregação como um mecanismo de "libertação" das obrigações familiares próprias do meio rural e como inserção em um universo rico de possibilidades, incluindo missões para países da África e Ásia. Concluindo sua análise acerca da vocação religiosa, Grossi menciona, ainda, que existe a proposta eclesiástica, elaborada pela Igreja, que tem a finalidade de reproduzir-se de forma material e simbólica em diversos locais como escolas, hospitais e comunidades, nas quais as freiras se tornam instrumento de propagação dos princípios cristãos e da fé católica.

Para traçar o perfil das Irmãs da congregação de Jesus na Santíssima Eucaristia foco de nossa pesquisa - seria necessária uma vasta documentação que, até o momento não tivemos acesso. Portanto, diante desse obstáculo, ou seja, a falta de fonte documental, tentaremos resgatar um pouco da história das religiosas por meio da conversa que empreendemos com cinco Irmãs que fazem parte do Instituto, na atualidade. ${ }^{14}$ É importante destacar que, embora nem todas tenham vivenciado o cotidiano da congregação no período em estudo ${ }^{15}$ - 1929 a 1950 - elas passaram a fazer parte da mesma alguns anos mais tarde e, de uma maneira bastante particular e ao mesmo tempo coletiva, emprestaram parte de suas memórias e histórias para a constituição desse estudo.

Analisando os dados das cinco religiosas com as quais conversarmos, constatamos que estas se enquadram na abordagem de Grossi (1990) em relação à origem e ao contexto familiar, conforme demonstrado na tabela:

\footnotetext{
${ }^{13} \mathrm{O}$ dote tem a finalidade de cobrir as despesas da moça durante o período do postulado, ou antes da realização dos votos no convento. Nesse período, que poderia durar de seis meses a um ano, as despesas da jovem correm por conta da família. Mesmo as congregações que afirmam a não exigência do dote possuem regra clara sobre a responsabilidade da família com as despesas das moças nessa etapa dos estudos. Além do dote a jovem deveria levar consigo o enxoval, que poderia variar de uma congregação para a outra, mas, geralmente, era composto de lençóis, toalhas, cobertor, saias, blusas, roupa íntima e uma calça comprida.

${ }_{14}$ Acreditamos que o método por nós utilizado não compromete a qualidade da pesquisa e os resultados obtidos.

15 Das Irmãs entrevistadas apenas Vitalina Veronica Binizioli, que antes atendia pelo nome religioso de Maria Pia Vicentina, trabalhou no hospital no período em que a pesquisa se insere. Todas as demais freiras faleceram. Por isso, a impossibilidade de ouvir os seus relatos.
} 
QUADRO 1: Perfil das religiosas da congregação de Jesus na Eucaristia

\begin{tabular}{|c|c|c|c|}
\hline RELIGIOSA & $\begin{array}{c}\text { LOCAL DE } \\
\text { NASCIMENTO }\end{array}$ & $\begin{array}{c}\text { NUMERO DE } \\
\text { IRMÃOS* }\end{array}$ & $\begin{array}{c}\text { ANO EM QUE } \\
\text { INGRESSOU NA } \\
\text { CONGREGAÇÃO }\end{array}$ \\
\hline Irmã V & $\begin{array}{c}\text { Muniz Freire (ES) } \\
\text { (Zona rural) }\end{array}$ & 8 & 1943 \\
\hline Irmã E & $\begin{array}{l}\text { Colatina (ES) } \\
\text { (Zona rural) }\end{array}$ & 9 & 1955 \\
\hline Irmã A & $\begin{array}{c}\text { Muniz Freire (ES) } \\
\text { (Zona rural) }\end{array}$ & 11 & 1956 \\
\hline Irmã O & $\begin{array}{c}\text { Oliveira (MG) } \\
\text { (Zona rural) }\end{array}$ & 14 & 1960 \\
\hline Irmã I & $\begin{array}{c}\text { Itaperuna (RJ) } \\
\text { (Zona rural) }\end{array}$ & 11 & 1961 \\
\hline
\end{tabular}

*Total do número de filhos em cada família. Fonte: arquivo pessoal da autora.

Além das cartas e circulares escritas por madre Gertrudes de São José às freiras da congregação, outro importante documento que norteou nossa pesquisa, foram as Constituições, também denominada de Regra de Vida, das Irmãs de Jesus na Santíssima Eucaristia, referentes ao período de 1932 a 1950. Tal documento regulava todas as esferas da vida das irmãs, desde a fisionomia até a postura do corpo. Conforme podemos observar abaixo:

$1^{\circ}$ - Que o aspecto da face seja sereno, calmo, aberto, acolhedor e, em geral, mais alegre do que triste;

$2^{\circ}$ - Que vossos olhares exprimam doçura, simplicidade, benevolência e um modo de recato;

$3^{\text {o }}$ - Não deixeis vossos olhares se divagarem ou sobre um objeto, ou sobre outro e que o movimento dos mesmos não seja nem muito frequente nem muito lânguido;

[...] $5^{\circ}$ - Não os lanceis jamais de maneira alguma, sobre pessoas de outro sexo, mas se necessário, que isto seje sem perturbação nem temos aparente, sempre com simplicidade e decência;

[...] $8^{\circ}$ - Evitai todo o movimento brusco da cabeça; 
$9^{\circ}$ - Não façais jamais sinal algum com os traços do rosto, da boca, com os olhos, etc para exprimir uma exprimir uma paixão ou uma afeição da alma, desgostos, aversão, etc;

[...] $11^{\circ}$ - Estando em pé, deixe o corpo direito e firme, sem esforço, nem pôse efeminada (Apêndice extraído das Constituições das Irmãs de Cristo Rei, 19321950).

Os momentos de recreação também eram ordenados de forma criteriosa por regras que tinham o objetivo de evitar conversas indesejadas que pudessem expressar sentimentos íntimos de amizades, inimizades ou contestações:

1 - Evitai, na recreação, certa indiferença, desleixo ou uma súbita expansão;

2 - Tende em igual aversão, tanto uma espécie de intemperança nas conversas, como um silêncio afetado;

[...] 4 - Tomai em conta a vossa idade e a vossa posição, para saberdes a parte que deveis tomar nas conversas;

5 - Não interrompais ninguém, sobre tudo, os vossos superiores;

6 - Jamais contestar coisa alguma, desviando agradavelmente a conversa, quando ela degenerar em contestação;

[...] 9 - Não faleis jamais de vos mesmas, nem bem, nem mal, ainda menos de vossas enfermidades ou penas;

[...] 15 - Não vos deixeis levar por gargalhadas estrondosas e imoderadas (Apêndice extraído das Constituições das Irmãs de Cristo Rei, 1932-1950).

Nessa perspectiva, um olhar superficial poderia caracterizar a hierarquia da congregação como despótica ou excessiva, entretanto, a mesma se baseava no modelo familiar que muitas jovens da zona rural estavam comumente habituadas. A relação entre Superiora e freiras se estabelecia a partir do modelo mãe/filha, conforme pudemos observar em carta da madre Gertrudes, quando ainda era noviça, datada de 12 de outubro de 1924, endereçada à sua Superiora, na qual inicia escrevendo: Boa e querida, Mãe. Anos mais tarde, a então madre Gertrudes, escreve em 2 de maio de 1947, às religiosas da comunidade da Santa Casa de Cachoeiro, na qual se refere às freiras da seguinte forma: Minhas queridas filhas da Santa Casa de Misericórdia de Cachoeiro de Itapemirim. Grossi (1990) destaca que, nessa teia de hierarquias, a madre representa a mãe, responsável por suas filhas, mas que depende, em diversos momentos, do apoio masculino de um prelado para resolver diversas questões pertinentes à congregação. Se por um lado a saída de casa rumo a uma carreira religiosa pode representar para muitas moças a independência do poder paterno, a congregação, com suas regras e normas, acabava reproduzindo o mesmo modelo organizacional das famílias da zona rural. 
Acreditamos que para a maioria das religiosas tanto da congregação em estudo, como das demais espalhadas pelo país, tratar sua trajetória dentro de um instituto religioso como profissão, com todos os encargos, anseios e frustrações comuns à qualquer outro trabalho desempenhado por determinado profissional é constrangedor e vai de encontro aos princípios cristãos de amor ao próximo e de abnegação. Por isso, para as freiras é mais confortável encarar a opção pela vida religiosa como um chamado ou vocação, mesmo que a mesma envolva escolhas pessoais e familiares, conforme analisamos no decorrer desse estudo.

\section{ATUAÇÃO DAS FREIRAS ENFERMEIRAS NA SANTA CASA DE CACHOEIRO}

Em 1916 ocorreu uma reunião da diretoria da Santa Casa de Cachoeiro sob a direção do então presidente Felinto Elysio Martins, na qual o mesmo declarou que a finalidade daquela sessão era deliberar sobre a conveniência de encarregar o serviço de enfermeiras do hospital às Irmãs de Caridade. A proposta foi colocada em votação e aprovada por unanimidade, mas não havia congregação, nem religiosas atuando em Cachoeiro, tampouco nos arredores, por isso apesar de aprovada a proposta não se efetivou.

Em 1929 a congregação das Irmãs de Jesus na Santíssima Eucaristia estava em pleno funcionamento. Atento ao trabalho das freiras junto à comunidade, o presidente da Santa Casa, Mário Rezende, escreveu uma carta à Superiora pedindo que estas, atuassem junto aos enfermos do hospital. O pedido foi aceito e publicada uma nota no jornal Correio do Sul em 07 de maio de 1929, informando sobre a entrega da direção interna do Hospital às irmãs, estando a superintendência geral sob os cuidados de madre Gertrudes de São José. A partir de então, as freiras passaram a trabalhar na Santa Casa em diversos setores, como: farmácia, enfermaria, lavanderia, cozinha, pediatria. Após dois dias o periódico publicou o contrato de serviço firmado entre a Madre e o Hospital. A seguir citaremos alguns trechos desse documento que possuía nove cláusulas:

$1^{a}$. A Irmã Gertrudes de São José, diretora do Colégio Sagrado Coração de Jesus, também designada primeira contratante, contrata com a Santa Casa de Misericórdia de Cachoeiro de Itapemirim, também designada contratante ou simplesmente Santa Casa, representada por seu presidente Mário Resende e devidamente autorizada por Assembleia Geral, a direção interna de todos os serviços, sem despesa alguma para a primeira contratante e sob as condições seguintes: 
$2^{\text {a }}$. A primeira contratante obriga-se a superintender todo o serviço interno das dependências da Santa Casa, inspecionando-os diariamente sob força maior e zelando para sua economia, limpeza, asseio, ordem e moralidade. Conforme dispõe o regulamento interno;

[...] $7^{\mathrm{a}}$. A segunda contratante obriga-se a dar às Irmãs uma alimentação boa, sadia [...] bem como no caso de doenças de qualquer delas, dar-lhes também além dos necessários medicamentos, a respectiva assistência médica e, verificando algum falecimento, serão por conta da Santa Casa todas as despesas de transporte e enterro;

$8^{\text {a }}$. A segunda contratante pagará a cada uma das Irmãs empregadas nos serviços da Santa Casa, inclusive à primeira contratante a importância mensal de $100 \$ 000$ (cem mil réis) e dará também mais $150 \$ 000$ (cento e cinquenta mil réis) mensalmente para serem aplicados nos seus serviços religiosos podendo a primeira contratante contratar capelão com as atribuições que achar pertinente;

9a. Este contrato terá vigor durante quatro anos a partir da data de sua assinatura e, se não for proposta a sua rescisão, será ele renovado por mais quatro anos e assim sucessivamente.

A residência das Irmãs era nas dependências da Santa Casa, embora não estivessem sob a vigilância direta da Superiora na Casa-mãe, havia um prédio destinado às freiras, denominado de clausura - com dependências semelhantes às da congregação - onde o acesso era restrito às religiosas. Apesar de não viverem em regime de claustro, madre Gertrudes se preocupava com os intercâmbios entre religiosas e leigos e as consequências desses relacionamentos na vida espiritual das Irmãs. Em carta coletiva - destinada a todas as religiosas da irmandade - de 10 de agosto de 1939 a Superiora alerta às freiras que se lembrem do capítulo $9^{\circ}$ das Constituições que determinava o seguinte:

Nenhuma Irmã poderá ter correspondência com qualquer que seja sem licença de sua Superiora e nem amizades particulares com pessoas religiosas, mesmo confessores, diretores, etc. Como também é proibido fazer ou receber presentes, entreter-se com conversas fiadas com qualquer secular, isto é, médicos, enfermeiros, empregados, etc., mesmo com sacerdotes fora do confessionário (Cartas de madre Gertrudes de São José, 10 de agosto de 1939).

Em outra carta de 09 de outubro de 1939 carta madre Gertrudes destaca a importância da obediência à determinação da Saúde Pública, que ordenou a todas as pessoas que tratavam com doentes, seja nas enfermarias, salas de operações e curativos, a vestirem-se de branco, segue escrevendo que em todos os hospitais onde havia atuação de membros da irmandade, as freiras deveriam usar um avental inteiro com mangas compridas e véu branco. Na mesma correspondência, a Superiora queixou-se que algumas religiosas não estavam acatando as 
determinações e como consequência de sua desobediência poderiam ser impedidas de renovarem os votos.

A partir de 1930 houve um intenso processo de institucionalização da enfermagem no país, exigindo dos profissionais que atuavam na área cursos de capacitação e aperfeiçoamento profissional. As Irmãs que atuavam em hospitais precisaram se adequar aos novos rumos da saúde pública. Nunes (1997) afirma que enquanto predominou na sociedade uma ideia sacralizada de mundo, as religiosas exerciam sem nenhuma ressalva, funções para as quais não estavam tecnicamente habilitadas, atuavam como professoras, enfermeiras e assistentes sociais. Mas a modernidade passou a exigir habilitação específica para o exercício de diversas profissões, o que dificultou a permanência das freiras nas diferentes obras em que atuavam, mesmo assim a participação das mesmas na área de assistência social continuou sendo exercida. A resposta das congregações a essa nova realidade foi o incentivo a profissionalização das religiosas.

As Irmãs que atuavam na Santa Casa de Cachoeiro passaram a buscar capacitações através de cursos de enfermagem, como forma de adequação aos novos rumos da saúde no país. No ano de 1946 - dia 08 de março - madre Gertrudes escreve às Irmãs Olívia e Celestina sobre a importância de ambas fazerem o curso de enfermagem superior na renomada escola Ana Nery no Rio de Janeiro, para obtenção de certificado. A Superiora fez questão de destacar na carta, que a prática adquirida na escola possuía muito valor nos hospitais.

A hipótese que defendemos é que a partir da institucionalização da enfermagem houve uma mudança no pressuposto do curar - praticado pelas Irmãs - para a perspectiva do curar, esperada de todos os profissionais que atuavam diretamente junto aos doentes. Isto posto, não bastava apenas ideais de caridade e amor ao próximo, para exercer a profissão de enfermeira, era preciso conhecimentos técnicos e científicos. Embora buscassem especialização em cursos de enfermagem, em diversos momentos os princípios religiosos a que estavam submetidas eram confrontados pelas mudanças na dinâmica do hospital. Em carta de madre Gertrudes à Irmã Elisa - diretora interna da Santa Casa - constatamos a preocupação da Superiora para que os doentes recebessem além dos sacramentos, conforto espiritual. Outrossim, a madre exorta as freiras enfermeiras sobre a postura destas em relação aos seculares: 
Eu queria saber notícias detalhadas sobre as Irmãs se cumprem bem o seu emprego, se são sérias com os médicos e empregados [...] se guardam a compostura religiosa com os seculares, ou se guardam alguma amizade particular [...] Agora vamos passar para outro assunto todo seu e particular. O dever de uma diretora hospitaleira são os seguintes: Todos os dias deve visitar os doentes tanto pensionistas como indigentes [...] confortá-los e aconselhá-los na recepção dos Santos Sacramentos para que ninguém morra sem eles (Cartas de madre Gertrudes de são José, 20 de agosto de 1951).

A partir da década de 1950 as freiras deixaram a administração do hospital. Segundo relatos da religiosa Aurora Côgo ${ }^{16}$ as Irmãs começaram a perceber que os demais funcionários reclamavam que estas possuíam privilégios dentro da Santa Casa, pois como ficavam o dia todo - e às vezes até a noite - trabalhando na instituição, se alimentavam da comida que era produzida pelo hospital e utilizavam os serviços da lavanderia. Mas para além dos conflitos e perseguições internas o que realmente estava acontecendo eram intensas transformações na sociedade que repercutiram no dia a dia do nosocômio. A demanda por atendimento aumentou significativamente o que acarretou a expansão do quadro de funcionários. Nesse período passaram a atuar no hospital enfermeiras e enfermeiros com formação técnica, seus valores e vivências iam de encontro aos ideais das religiosas, que eram proibidas de manter amizades com seculares. As Irmãs enfermeiras eram sobretudo freiras, doutrinadas por rígidos estatutos de uma congregação religiosa. A partir do momento em que as atribuições na Santa Casa entraram em conflito com o seu chamado espiritual, as mesmas não hesitaram em migrar para outras áreas de atuação.

\section{REFERÊNCIAS:}

\section{Documentação Primária}

Constituições das Irmãs de Cristo Rei (1932 -1950). Cachoeiro de Itapemirim.

Livro de Inscrição e Matrícula das Irmãs de Jesus na Santíssima Eucaristia (1927-2008).

MADRE GERTRUDES DE SÃO JOSÉ. Cartas. Congregação das Irmãs de Jesus na Eucaristia (maio de 1937 a junho de 1962). Belo Horizonte: Editora São Vicente, 1981.

\footnotetext{
${ }^{16}$ Membro da irmandade desde a década de 1960, tem procurado preservar a história da congregação através da concessão de entrevistas e arquivamento de documentos.
} 


\section{Material Bibliográfico}

ALGRANTI, Leila Mezan. Honradas e devotas: mulheres da colônia. Condição feminina nos conventos e recolhimentos do Sudeste do Brasil, 1750-1822. Rio de Janeiro: José Olympo, 1993.

BARDY. L'attitude politique de saint Césaire d'Arles. Revue d'histoire de l'Église de France, Louvain, v. 33, n. 123, p. 241-56, 1947.

BEZERRA, Maria Luiza. A Enfermagem e a Aliança da Igreja com o Estado: Escola de Enfermeiras Luiza de Marillac. Dissertação (em História da Enfermagem) Escola de Enfermagem Anna Nery/UFRJ, Rio de Janeiro, 2002.

BROWN, Peter. Santo Agostinho: uma biografia. Rio de janeiro: Record, 2005.

CAETANO, Dalila. Coração inquieto. Belo Horizonte: Copigráfica, 2016.

CASTRO, J. C. M. Vida de Luiza de Marillac: fundadora das irmãs de caridade. Petrópolis (RJ): Vozes; 1936.

DONAHUE, Patricia. Historia de la Enfermeria. St Louis (MI): Mosby Company, 1993.

FERNANDES, Maria Eugenia Matos. O Mosteiro de Santa Clara do Porto em meados do século XVIII (1730-1780). Porto: Arquivo Histórico Câmara Municipal, 1992.

FRATTINI, Eric. Os espiões do Papa. Lisboa: Bertrand Editora, 2009.

GIORDANI, Mario Curtis. História da Grécia. Petrópolis: Vozes, 1972.

GROSSI, Miriam Pillar. Jeito de freira: estudo antropológico sobre a vocação religiosa feminina. Caderno de Pesquisa São Paulo. n. 73, pp. 48-58, maio/1990.

LANGLOIS, Claude. Le catholicisme au féminin. Les congrégations françaises à supérieure générale au XIXe siècle. Paris: Les Editions du Cerf, 1984. LEITE, Serafim. História da Companhia de Jesus no Brasil, Rio de Janeiro: Civilização Brasileira, 1938. 
LEONARDI, Paula. Congregações católicas e educação: o caso da sagrada família de Bordeaux. Revista Brasileira de História Educacional. Campinas, (SP), v. 11, n.2(28), pp. 103-120, mar./ago. 2011.

MOURA, Maria Margarida. Os herdeiros da terra. São Paulo: Hucitec, 1978.

NUNES, Maria José Rosado. Freiras no Brasil. In: DEL PRIORE, Mary (Org.). História das mulheres no Brasil. São Paulo: Contexto, 1997.

PADILHA, Maria Itayra Coelho Souza; MANCIA, Joel Rolim. Florence Nigthingale e as irmãs de caridade: revisitando a história. Revista Brasileira de Enfermagem. Brasília, n. 58(6), pp. 723-6, 2005.

SÃO JOSÉ, Angelina de. et al. Morte de um Grão Certeza de Vida. Belo Horizonte: Imprimatur, 1990.

SEIDL, Ernesto. Sociologia da vocação religiosa: reprodução familiar e reprodução da Igreja. Revista Sociologias, Porto Alegre, v. 14, n. 29, pp. 240-272, jan./abr., 2012.

SUAUD, Charles. La vocation: conversion et reconversion des prêtres ruraux. Paris: Minuit, 1978.

WOLLPERT, Rudolf. Os Papas. Petrópolis: Vozes, 1998. 